\title{
Analisis Pengaruh Penciptaan Pengetahuan terhadap Kinerja Organisasi di Kalangan Usaha Kecil Menengah
}

\author{
Rinawati Zailani \\ Sekolah Tinggi dan Ilmu Pendidikan (STIKIP) Catur Sakti Yogyakarta \\ Choirun Nisaa' \\ Sekolah Tinggi dan Ilmu Pendidikan (STIKIP) Catur Sakti Yogyakarta \\ rinawati.zailani@gmail.com
}

\begin{abstract}
Abstrak
Penelitian ini bertujuan untuk menguji pengaruh penciptaan pengetahuan terhadap kinerja organisasi. Usaha Kecil Menengah (UKM) sektor makanan lekat dengan pengetahuan implisit, sehingga perlu identifikasi pengaruh pengetahuan implisit untuk kemajuan bisnis. Penelitian ini dilakukan pada Usaha Kecil Menengah sektor makanan di provinsi Yogyakarta. Sampel dalam penelitian ini berjumlah 76 pelaku usaha di UKM sektor makanan yang diperoleh berdasarkan survei dengan menyebarkan 90 kuisioner. Metode analisis yang digunakan yaitu analisis regresi sederhana untuk pengujian hipotesis. Hasil penelitian menunjukkan bahwa penciptaan pengetahuan berpengaruh positif terhadap kinerja organisasi. Dalam tahapan penciptaan pengetahuan, hanya faktor kombinasi pengetahuan yang berpengaruh positif dan signifikan terhadap kinerja organisasi, lainnya yaitu tahap sosialisasi, eksternalisasi, dan internalisasi tidak ada pengaruh terhadap kinerja organisasi.
\end{abstract}

Kata kunci: Sosialisasi, eksternalisasi, kombinasi, internalisasi, kinerja.

\section{Pendahuluan}

Suatu perusahaan baik besar maupun kecil, berupaya untuk lebih kreatif dalam mengelola usaha berdasar sumberdaya yang dimiliki (Durst dan Edvardsson 2012). Menurut Grant (1996), inti dari sumberdaya perusahaan adalah pengetahuan. Pengetahuan merupakan proses pembenaran keyakinan individu pada suatu hakikat (Nonaka dan Takeuchi 1995).

Menurut Durst dan Edvardsson (2012), pengelolaan pengetahuan di Usaha Kecil Menengah (UKM) masih memerlukan perhatian lebih. UKM perlu memperhatikan pengelolaan pengetahuan karena UKM merupakan usaha dengan kondisi yang mudah berubah sehingga harus berusaha optimal untuk mencapai kegiatan operasional yang unggul (Indarti 2010). Penelitian Song dan Chermark (2008), serta Ramirez (2012), pengetahuan akan menjadi aset berharga ketika pengetahuan tersebut melekat dalam organisasi, sehingga dapat dijadikan faktor kritis untuk peningkatan kinerja dan keunggulan kompetitif.

Eksplorasi pengetahuan, khususnya pengetahuan implisit masih membutuhkan penjelasan lebih banyak dalam domain manajemen pengetahuan (Venkitachalam dan Busch 2012). Pengetahuan implisit mengandung dimensi kognitif, yang berisi model mental, kepercayaan, dan persepsi (Nonaka dan Takeuchi 1995). Penelitian ini membahas peran pengetahuan terhadap organisasi yaitu pengaruh penciptaan pengetahuan terhadap kinerja organisasi. Beberapa penelitian terdahulu telah mengidentifikasi keterkaitan pengetahuan maupun informasi terhadap kinerja organisasi (King dan Ko 2001 dalam Chou dan Tsai 
2004; Ramirez et al. 2012; Cloyd 1995; Filip et al. 1999). Reviu Venkitachalam dan Busch (2012), mengarahkan untuk mengidentifikasi peran pengetahuan implisit dalam organisasi.

Penelitian dilakukan di UKM sektor makanan karena perkembangan UKM yang terus mengalami peningkatan (Hakim 2013). Hal tersebut menunjukkan bahwa pelaku usaha menggunakan pengetahuan yang dimiliki untuk menciptakan produk makanan yang beraneka ragam. UKM sektor makanan merupakan salah satu bidang usaha yang cenderung menggunakan pengetahuan implisit karena resep dan cita rasa makanan berada dalam benak individu pembuatnya. Menurut pelaku usaha makanan, semua orang dapat membuat makanan dan menirunya, tetapi tidak banyak yang sukses dari produk makanan yang dibuatnya (Kitty 2011).

Berdasarkan latar belakang tersebut, penelitian ini bertujuan untuk mengidentifikasi peran penciptaan pengetahuan terhadap kinerja organisasi, dengan mengidentifikasi faktor penciptaan pengetahuan yang berupa Sosialisasi, Eksternalisasi, Kombinasi, dan Internalisasi. Secara detail, penelitian ini akan menjawab beberapa pertanyaan, yaitu: 1) Apakah Sosialisasi pengetahuan berpengaruh positif terhadap kinerja organisasi UKM? 2) Apakah Eksternalisasi pengetahuan berpengaruh positif terhadap kinerja organisasi UKM? 3) Apakah Kombinasi pengetahuan berpengaruh positif terhadap kinerja organisasi UKM? Dan 4) Apakah Internalisasi pengetahuan berpengaruh positif terhadap kinerja organisasi UKM?

\section{Landasan Teori dan Pengembangan Hipotesis}

Suatu organisasi dapat bertahan dan mempertahankan keunggulan kompetitif karena mempunyai perspektif dalam organisasi, baik perspektif ketergantungan sumberdaya, perspektif efisiensi, maupun perspektif populasi (Ulrich dan Barney 1984). Berdasar perspektif sumberdaya, menurut Wernerfelt (1984), dengan memahami sumberdaya, suatu perusahaan memiliki daya tawar, yang tidak hanya berasal dari produk yang dihasilkan. Barney (1991), menyatakan bahwa sumberdaya yang memiliki daya tawar merupakan sumberdaya yang bernilai, langka, tidak dapat disubstitusi, dan tidak dapat ditiru organisasi lain. Grant (1996), merumuskan konsep bahwa inti dari sumberdaya perusahaan adalah pengetahuan. Menurut Chou dan Tsai (2004), pengetahuan dalam organisasi berpengaruh terhadap kinerja yang merupakan tujuan suatu organisasi.

Kinerja organisasi merupakan indikator tingkatan prestasi yang dapat dicapai organisasi dan mencerminkan keberhasilan manajer/pengusaha (Soedjono 2005). Berdasar penelitian Fening et al. (2008), dalam meningkatkan kinerja organisasi, pemilik/manajer UKM perlu memperhatikan beberapa hal, antara lain: kepemimpinan, rencana strategis, sumberdaya manusia, pelanggan, informasi dan analisis, manajemen proses, kualitas, serta hasil operasional. Pengukuran kinerja dapat dilakukan dengan identifikasi kegiatan finansial dan kegiatan multidimensional. Berdasar kajian literatur Carmen et al. (2012), pengukuran kinerja melalui segi finansial saja akan melewatkan dua hal, yaitu: 1) kinerja organisasi bergantung pada campuran kapabilitas organisasi dan sulit digambarkan dalam hubungan langsung yang jelas, 2) kinerja organisasi berhubungan dengan industri dan isu ekonomi secara makro. Berdasarkan hal tersebut, untuk mempertimbangkan pengukuran finansial dan multidimensional, maka penelitian ini menggunakan pengukuran Maltz et al. (2003) dalam Tseng (2010), yang merumuskan lima indikator kinerja organisasi dengan mengukur persepsi, yaitu kinerja finansial, pasar/pelanggan, proses, pengembangan karyawan, dan antisipasi masa depan.

Penciptaan pengetahuan organisasi yaitu tahapan-tahapan untuk membuat pengetahuan lebih mudah diakses baik dari level individu, kelompok, hingga dalam 
organisasi (Nonaka et al. 2006; Byosiere dan Luethge 2008). Menurut Lam (2000), Pengetahuan implisit dan eksplisit diklasifikasikan dalam tiga area yang berbeda, yaitu:

a) Perbedaan dalam hal kemampuan kodifikasi dan mekanisme transfer. Pengetahuan eksplisit dapat dikodifikasi, dapat dipahamai, disimpan, dan dibagi tanpa mengetahui subjeknya. Kelebihan pengetahuan eksplisit yaitu kemudahan dalam komunikasi dan transfer. Pengetahuan implisit merupakan intuisi dan tidak dapat diartikulasikan, sulit dikomunikasikan dan dimengerti tanpa mengetahui subjeknya. Transfer pengetahuan implisit membutuhkan interaksi yang kuat dan perlu membangun kepercayaan dan pemahaman yang lebih dalam proses transfer.

b) Perbedaan cara akuisisi dan akumulasi pengetahuan. Pengetahuan eksplisit dihasilkan melalui proses deduksi logis dan sistem belajar formal, sedangkan pengetahuan implisit hanya diperoleh dari pengalaman dan praktek.

c) Perbedaan dalam hal pengumpulan dan cara transfer. Pengetahuan eksplisit dapat dikumpulkan dalam satu tempat, disimpan dalam bentuk yang objektif, dan cara transfer tidak perlu partisipasi subjek, sedangkan pengetahuan implisit sulit dikumpulkan karena melekat pada individu, dan memerlukan keterlibatan serta kerjasama dengan subjek penerima.

Penciptaan pengetahuan menurut Nonaka dan Tekeuchi (1995), merupakan perubahan pengetahuan dari implisit menjadi eksplisit kemudian menjadi implisit kembali dalam organisasi. Penciptaan pengetahuan dalam organisasi dipengaruhi oleh strategi organisasional, proses pembelajaran organisasi, lingkungan organisasi, dan sistematik manajemen pengetahuan (Song dan Chermark 2008).

Perputaran pengetahuan implisit ke eksplisit tersebut dikenal dengan model SECI (Sosialisasi, Eksternalisasi, Kombinasi, dan Internalisasi). Perubahan pengetahuan (SECI model) berdasar konsep Nonaka dan Takeuchi (1995) yaitu:

a) Tahap Sosialisasi (Socialization), merupakan perputaran pengetahuan dari implisit ke implisit, yang mana pengetahuan diperoleh dari observasi, meniru, atau praktek langsung.

b) Tahap Eksternalisasi (Externalization), merupakan perubahan pengetahuan implisit menjadi pengetahuan eksplisit, tercermin dari adanya simbol, tulisan, dokumentasi, konsep ataupun model.

c) Tahap Kombinasi (Combination), merupakan perubahan pengetahuan eksplisit menjadi eksplisit seperti penggandaan model, dokumentasi, maupun pengklasifikasian kembali.

d) Tahap Internalisasi (Internalization), merupakan perubahan pengetahuan eksplisit menjadi pengetahuan implisit, yang digambarkan pengetahuan organisasi melekat dalam aturan, rutinitas, norma-norma dan kebiasaan dalam organisasi.

Penelitian Tseng (2010), menunjukkan bahwa penciptaan pengetahuan memberikan peluang dalam mengkomunikasikan ide, pengetahuan, dan pengalaman, sehingga dapat meningkatkan kinerja organisasi. Song (2008), menyatakan bahwa penciptaan pengetahuan yang meliputi berbagi pengetahuan, pembangunan pengetahuan, dan pengklarifikasian pengetahuan berpengaruh pada peningkatan kinerja organisasi. Berdasarkan beberapa penelitian tersebut, maka dirumuskan hipotesis sebagai berikut: 
a. H1 : Sosialisasi pengetahuan berpengaruh positif terhadap kinerja organisasi

b. H2 : Eksternalisasi pengetahuan berpengaruh positif terhadap kinerja organisasi

c. H3 : Kombinasi pengetahuan berpengaruh positif terhadap kinerja organisasi

d. H4 : Internalisasi pengetahuan berpengaruh positif terhadap kinerja organisasi

Model penelitian ini menjelaskan bahwa pemimpin (pemilik/manajer UKM yang memiliki pengetahuan), akan menciptakan pengetahuan yang digunakan untuk meningkatkan kinerja organisasi dalam UKM. Pemilik/Manajer UKM merupakan aktor utama penggerak bisnis, sehingga akan memanfaatkan pengetahuan yang dimiliki untuk kemajuan usahanya.

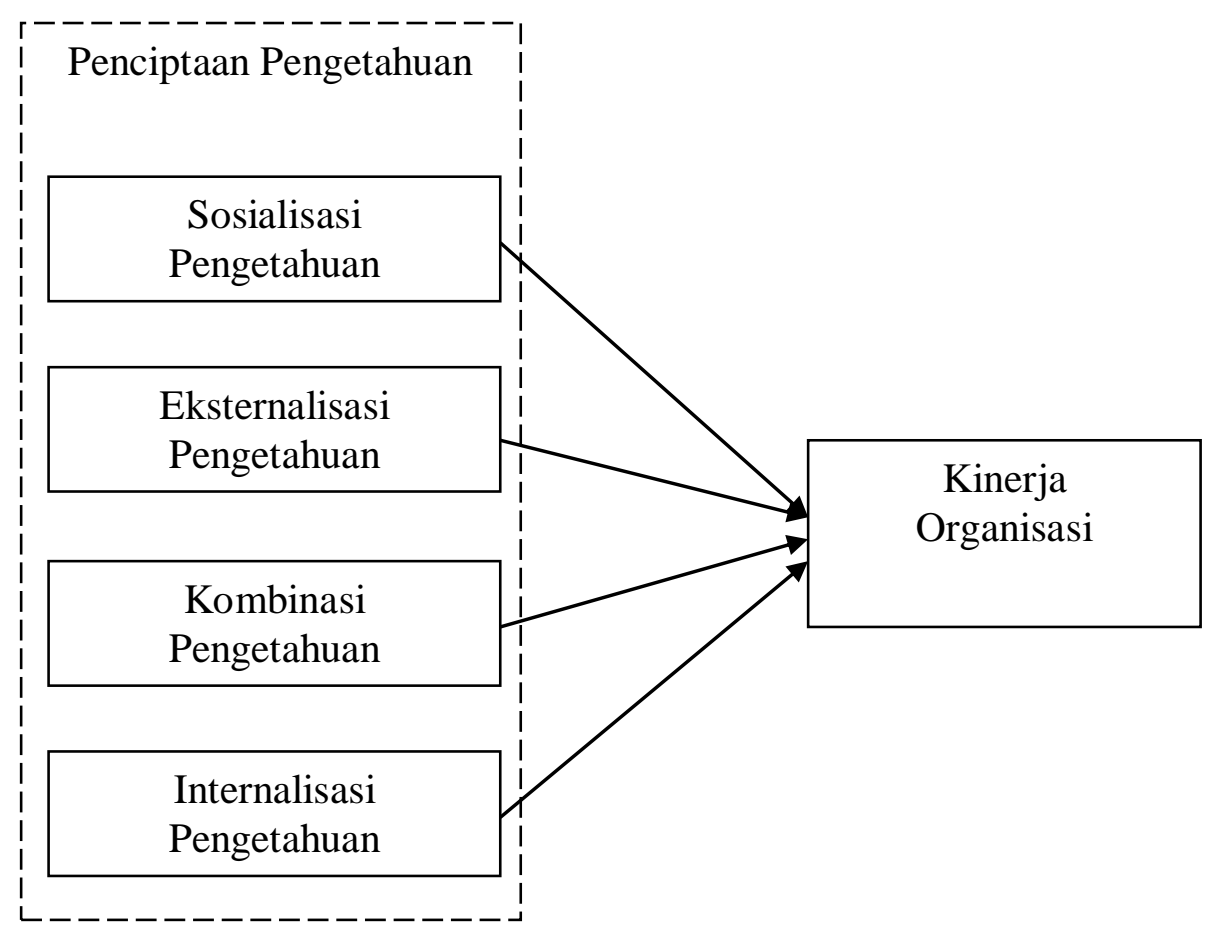

Gambar 1. Model Penelitian

\section{Metode Penelitian}

Desain penelitian ini menggunakan pendekatan kuantitatif dengan teknik survei, menyebarkan kuisioner dan metode penyampelan purposive judgment. Data yang digunakan merupakan data silang (cross sectional), dengan teknik snowballing. Kriteria yang ditetapkan untuk kualifikasi responden yaitu pemilik/ manajer UKM sektor makanan yang telah berdiri minimal 3 tahun, memiliki karyawan sebanyak 5-99 orang, dan memiliki ijin usaha serta lolos dinas kesehatan.

Pengumpulan data dilakukan dengan mendistribusikan kuesioner melalui survei. Kuisioner yang disebar sebanyak 90 kuisioner, dan yang kembali sebanyak 76 kuisioner atau mempunyai tingkat respon $84,44 \%$.

Penciptaan pengetahuan yaitu tahapan-tahapan untuk membuat pengetahuan agar lebih mudah diakses dan memperkuat penciptaan pengetahuan dari individu dengan cara menghubungkan dengan sistem pengetahuan organisasi (Nonaka et al. 2006). Konstruk ini diukur dengan 25 item yang mengukur penciptaan pengetahuan organisasi (Tseng 2010; 
Ramirez et al. 2011; dan Ramirez et al. 2012), Tahap Sosialisasi 7 item, tahap Eksternalisasi 6 item, tahap Kombinasi 6 item, dan tahap Internalisasi 6 item. Skala yang digunakan yaitu 5 point Skala Likert ( 1 = sangat jarang; sampai dengan $5=$ sangat sering). Salah satu contoh item penciptaan pengetahuan yaitu: "anggota organisasi saya dapat mengekspresikan pengetahuan yang dimilikinya melalui diskusi lisan dan tertulis".

Kinerja organisasi merupakan indikator tingkatan prestasi yang dapat dicapai organisasi dan mencerminkan keberhasilan manajer/pengusaha (Soedjono 2005). Pengukuran kinerja diukur dengan beberapa indikator yaitu kinerja keuangan, pasar/konsumen, proses, pengembangan karyawan, dan masa depan (Maltz et al. 2003, dalam Tseng 2010). Konstruk ini diukur dengan 13 item yang mengukur kinerja berdasar penelitian Tseng (2010). Skala yang digunakan yaitu 5 point Skala Likert $(1=$ sangat jarang; sampai dengan $5=$ sangat sering). Salah satu contoh item kinerja organisasi yaitu: "usaha kami dapat mencapai target penjualan produk".

Uji validitas dalam penelitian ini dilakukan dengan menggunakan SPSS 16.0 dengan metode Confirmatory Factor Analysis (CFA). Berdasar pengujian yang telah dilakukan, didapatkan nilai KMO-MSA sebesar 0.814 dan signifikansi Bartlett's Test sebesar 0,000. Hasil tersebut mengindikasikan bahwa kuisioner valid..

Pengujian reliabilitas menggunakan metode internal consistency yang menggunakan kriteria Cronbach's Alpha. Berdasar analisis, diketahui bahwa seluruh variabel lolos uji reliabilitas dengan ditunjukkan nilai Cronbach's Alpha diatas 0,7.

Tabel 1. Hasil Pengujian Reliabilitas

\begin{tabular}{|c|c|c|}
\hline Variabel & $\begin{array}{c}\text { Nilai Cronbach's } \\
\text { Alpha }\end{array}$ & Keterangan \\
\hline $\begin{array}{l}\text { Sosialisasi } \\
\text { Pengetahuan }\end{array}$ & 0,815 & Reliabel \\
\hline $\begin{array}{l}\text { Eksternalisasi } \\
\text { Pengetahuan }\end{array}$ & 0,826 & Reliabel \\
\hline $\begin{array}{l}\text { Kombinasi } \\
\text { Pengetahuan }\end{array}$ & 0,747 & Reliabel \\
\hline $\begin{array}{l}\text { Internalisasi } \\
\text { Pengetahuan }\end{array}$ & 0,702 & Reliabel \\
\hline Kinerja Organisasi & 0,810 & Reliabel \\
\hline
\end{tabular}

Sumber: Data primer diolah (2020)

\section{Pembahasan}

Pengujian hipotesis menguji variabel penciptaan pengetahuan yaitu Sosialisasi pengetahuan, Eksternalisasi pengetahuan, Kombinasi pengetahuan, dan Internalisasi pengetahuan sebagai variabel independen dan kinerja organisasi sebagai variabel dependen. Hasil pengujian menunjukkan bahwa hipotesis pertama, variabel Sosialisasi pengetahuan menunjukkan hasil yang tidak signifikan $(\beta=0,160 ; t=1,347$; Sig. $=0,182)$, yang berarti Sosialisasi pengetahuan tidak berpengaruh signifikan pada kinerja organisasi. Pada hipotesis kedua, variabel Eksternalisasi pengetahuan, nilai koefisien $\beta$ dan signifikansi juga tidak menunjukkan hasil yang signifikan $(\beta=-0,114 ; t=-0,745$; Sig. $=0,459)$, yang berarti Eksternalisasi pengetahuan tidak berpengaruh signifikan pada kinerja organisasi. Namun pada uji hipotesis ketiga, pengaruh antara Kombinasi pengetahuan dan kinerja organisasi, 
nilai koefisien $\beta$ dan signifikansi menunjukkan hasil yang positif signifikan $(\beta=0,494 ; t=$ 2,777; Sig. $=0,007)$, yang berarti Kombinasi pengetahuan berpengaruh positif signifikan pada kinerja organisasi. Sedangkan hipotesis keempat, Internalisasi pengetahuan nilai koefisien $\beta$ dan signifikansi juga tidak menunjukkan hasil yang signifikan $(\beta=0,158 ; t=$ $1,049$; Sig. $=0,298)$, yang berarti Internalisasi pengetahuan tidak berpengaruh signifikan pada kinerja organisasi.

Tabel 2. Hasil Uji Hipotesis

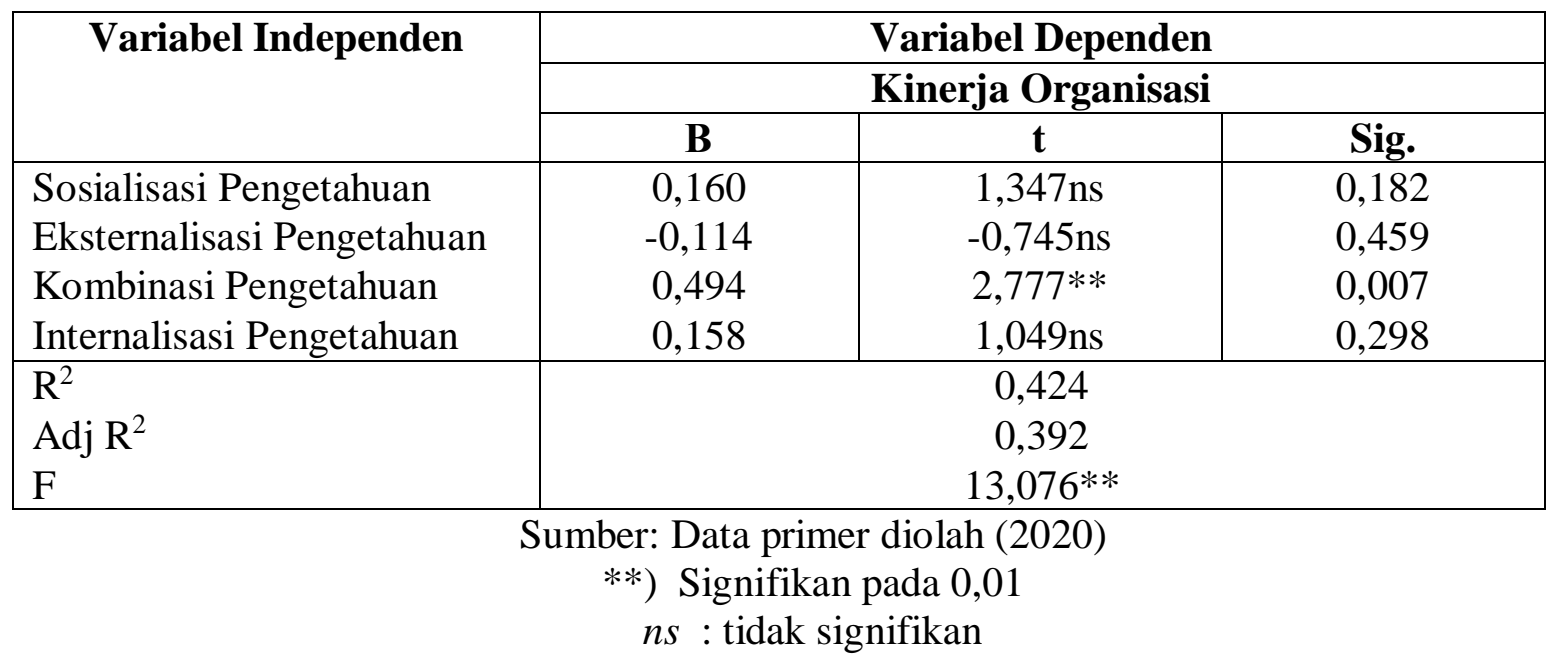

Berdasarkan analisis pengujian hipotesis yang telah dilakukan, hasil keseluruhan hipotesis terangkum dalam tabel sebagai berikut:

Tabel 3. Rangkuman Hasil Pengujian Hipotesis

\begin{tabular}{|c|c|c|c|}
\hline No & Hipotesis & Hasil Temuan & Kesimpulan \\
\hline 1 & $\begin{array}{l}\text { Sosialisasi pengetahuan berpengaruh } \\
\text { positif pada kinerja organisasi }\end{array}$ & Positif, tidak signifikan & $\begin{array}{l}\text { Hipotesis tidak } \\
\text { didukung }\end{array}$ \\
\hline 2 & $\begin{array}{l}\text { Eksternalisasi pengetahuan } \\
\text { berpengaruh positif pada kinerja } \\
\text { organisasi }\end{array}$ & Positif, tidak signifikan & $\begin{array}{l}\text { Hipotesis tidak } \\
\text { didukung }\end{array}$ \\
\hline 3 & $\begin{array}{l}\text { Kombinasi pengetahuan berpengaruh } \\
\text { positif pada kinerja organisasi }\end{array}$ & Positif, signifikan & Hipotesis didukung \\
\hline 4 & $\begin{array}{l}\text { Internalisasi pengetahuan } \\
\text { berpengaruh positif pada kinerja } \\
\text { organisasi }\end{array}$ & Positif, tidak signifikan & $\begin{array}{l}\text { Hipotesis tidak } \\
\text { didukung }\end{array}$ \\
\hline
\end{tabular}

Sumber: Data primer diolah (2020)

Penciptaan pengetahuan menurut Nonaka dan Takeuchi (1995), merupakan perubahan pengetahuan dari implisit menjadi eksplisit kemudian menjadi implisit kembali. Dalam penelitian ini, penciptaan pengetahuan dapat berpengaruh terhadap kinerja organisasi yaitu pada sektor makanan. Berdasar analisis yang dilakukan, hanya tahap kombinasi pengetahuan yang berpengaruh signifikan terhadap kinerja. Pembahasan hal tersebut yaitu: 
1) Pada tahap sosialisasi pengetahuan tidak berpengaruh terhadap kinerja organisasi. Sosialisasi pengetahuan merupakan perubahan pengetahuan dari implisit ke implisit, yang diperoleh dari proses observasi, meniru, atau praktek langsung. UKM sektor makanan dalam penelitian ini tahap sosialisasi pengetahuan tidak berpengaruh terhadap kinerja organisasi. Hal tersebut dapat terjadi karena ilmu memasak ataupun resep makanan sulit untuk ditiru maupun praktek langsung karena ilmu atau resep makanan terlalu implisit sehingga sulit ditransfer secara implisit, baik dengan praktek langsung, observasi maupun meniru.

2) Pada tahap eksternalisasi pengetahuan tidak berpengaruh terhadap kinerja organisasi. Eksternalisasi pengetahuan merupakan perubahan pengetahuan dari implisit menjadi eksplisit, tercermin dari adanya simbol, tulisan, gambar, konsep, atau model. Pada penelitian ini, tahapan tersebut tidak berpengaruh karena pemegang resep makanan atau pemegang prosedur pembuatan makanan tidak menggambarkan dan tidak menuliskan resep atau prosedur. Mayoritas standar operasional prosedur tidak tertulis, hanya lisan saja sehingga anggota organisasi tidak dapat menangkap pesan dengan jelas, pada akhirnya tidak berpengaruh terhadap kinerja.

3) Pada tahap kombinasi pengetahuan berpengaruh signifikan terhadap kinerja organisasi. Kombinasi pengetahuan merupakan perubahan pengetahuan dari eksplisit menjadi eksplisit, seperti penggandaan model, dokumentasi, maupun pengklarifikasian kembali. Pada penelitian ini kombinasi pengetahuan terjadi dari resep makanan atau prsedur makanan yang sudah tertulis kemudian dapat dibagikan kepada anggota organisasi, sehingga dapat meningkatkan kinerja. Selain itu, kombinasi pengetahuan terjadi dengan cara klarifikasi kembali kepada pemberi pesan/ilmu untuk dapat menuliskan maupun mempraktekkan kembali.

4) Pada tahap internalisasi pengetahuan tidak berpengaruh terhadap kinerja organisasi. Internalisasi pengetahuan merupakan perubahan pengetahuan dari eksplisit menjadi implisit, yang melekat dalam organisasi, seperti aturan, rutinitas norma dan kebiasaan dalam organisasi. Dalam penelitian ini, UKM sektor makanan tidak menuliskan resp maupun aturan sehingga internalisasi pengetahuan tidak terjadi.

Hasil penelitian ini menunjukkan bahwa hanya kombinasi pengetahuan yang berpengaruh terhadap kinerja organisasi. Hal tersebut dapat terjadi karena terdapat hambatan dalam proses transfer, penyebaran, dan berbagi pengetahuan dalam UKM sektor makanan. Hambatan tersebut dapat berasal dari sumber pengetahuan, motivasi yang rendah, keadaan organisasi, dan karakteristik pengetahuan tersebut. Selain itu, gagalnya proses transfer dapat disebabkan oleh hambatan dalam waktu, jarak, persepsi, maupun nilai dari pengetahuan. Hal tersebut dapat terjadi dalam kasus UKM sektor makanan karena: 1) kurangnya motivasi dari sumber pengetahuan, yaitu pemilik/manajer UKM takut jika karyawan mengetahui resep produk usaha yang ditekuni, akan keluar dan menjadi pesaing bagi pemilik/manajer UKM tersebut, 2) kurangnya antusias dari penerima pengetahuan yaitu karyawan, yang mana karyawan susah mengingat atau terlalu nyaman pada pengetahuan yang biasa digunakan, 3) hambatan dari jenis pengetahuan yang ditransfer atau dibakukan menjadi pengetahuan organisasi, yang mana pengetahuan tersebut memiliki sifat ambigu dan tidak nyata.

\section{Kesimpulan}

Penelitian ini membuktikan bahwa penciptaan pengetahuan berpengaruh pada kinerja organisasi pada tahap kombinasi pengetahuan. Kombinasi pengetahuan merupakan 
perubahan pengetahuan eksplisit menjadi eksplisit seperti penggambaran model, dokumen yang diperbanyak dan disebarkan ke seluruh anggota organisasi. Pengetahuan yang telah diperbanyak dan disebar kepada anggota memudahkan anggota melaksanakan tugas sesuai peraturan yang pada akhirnya dapat memajukan organisasi. Proses kombinasi pengetahuan di UKM sektor makanan dapat terjadi dengan cara memperbanyak resep, klarifikasi prosedur pada pemilik/manajer UKM. Hasil penelitian ini menunjukkan bahwa untuk meningkatkan kinerja organisasi dalam hal ini UKM sektor makanan, pemilik/manajer UKM perlu meningkatkan tahap kombinasi pengetahuan karena kombinasi pengetahuan dapat berpengaruh langung pada kinerja.

Penelitian ini masih memiliki banyak kekurangan, sehingga penelitian selanjutnya diharapkan dapat menambah jumlah sampel, membandingkan pada UKM sektor lain, dan dapat memasukkan variabel lain seperti inovasi sebagai variabel mediasi.

\section{Daftar Pustaka}

Ahsan, M, M. Ozer, dan E. Alakent. 2010. Incumbents adaptation to Competence-Destroying Change: Role of Prior Experience and Knowledge Sourcing. Journal of Managerial Issues, 22/4: 456-475.

Augier, M, dan M.T. Vendelu. 1999. Networks, cognition and management of tacit knowledge. Journal of Knowledge Management, 3/4: 252-261.

Barney, J. 1991. Firm resources and sustained competitive advantage. Journal of Management, 17/1: 99-120.

Byosiere, P, dan D.J. Luethge. 2008. Knowledge domains and knowledge conversion: an empirical investigation. Journal of Knowledge Management, 12/2: 67-78.

Carmen, P.C, T.G. Cruz, dan S.C. Ros. 2012. Do family SME managers value marketing capabilities' contribution to firm performance?. Marketing Intelligence \& Planning, 30/2: 116-142.

Chilton, M.A, dan J.M. Bloodgood. 2010. Adaption-innovation theory and knowledge use in organizations. Management Decision, 48/8: 1159-1180.

Chou, S.W, dan Y.H. Tsai. 2004. Knowledge creation: Individual and organizational perspectives. Journal of Information Science, 30/3: 205-218.

Cloyd, C.B. 1995. Prior knowledge, information search behaviors, and performance in tax research tasks. The Journal of the American Taxation Association, $17: 82$.

Durst, S, dan I.R, Edvardson. 2012. Knowledge management in SMEs: a literature review. Journal of Knowledge Management, 16/6: 879-903.

Fening, F.A, G. Pesakovic, dan P. Amaria. 2008. Relationship between quality management practices and the performance of small and medium size enterprises (SMEs) in Ghana. International Journal of Quality \& Reliability Management, 25/7: 694-708.

Filip, D, S. Mien, dan B. Michelle. 1999. The relation between assessment practices and outcome. Reviewof Educational Research, 69/2: 145-186.

Gibson, J.L, J.M. Ivancevich, J.H. Donnelly, dan R. Konopaske. 2009. Organizations: behavior, structure, processes. Mc Graw Hill.

Gold, A.H, M. Arvind, dan A.H. Segars. 2001. Knowledge management: An organizational capabilities perspective. Journal of Management Information Systems, 18/1: 185-214.

Grant, R.M. 1996. Toward a knowledge-based theory of the firm. Strategic Management Journal, 17: 109-122.

Hair, J.F., A.R.L. Tatham, and W.C. Black. 2010. Multivariate Data Analysis: Global Perspective (7th edition). New Jersey: Prentice Hall. 
Rinawati Zailani, Choirun Nisaa'

Hakim, L. 2013.Jumlah UKM di DIY Meningkat. Diakses dari http://www.antarajogja.com/jumlah-ukm-di-diy-meningkat.html pada tanggal 22 Desember 2013.

Indarti, N. 2010. The Effect of Knowledge Stickiness and Interaction on Absorptive Capacity: Evidence from furniture and software Small and Medium Enterprises in Indonesia. Disertasi (tidak dipublikasikan). Groningen: University of Groningen.

Kitty, T. 2011. Produk Ditiru? Siapa Takut? Diakses dari http://www.tarryholic.blogspot.com/2011/12/produk-ditiru-siapa-takut.html pada tanggal 13 Juni 2014.

Lam, A. 1998. Tacit knowledge, organisational learning and innovation: a societal perspective. DRUID Working Paper, no. 98-22: 1-61.

Liyanage, S, dan R. Bernard. 2003. Valuing of firms' prior knowledge: a measure of knowledge distance. Knowledge and Process Management,10/2: 85-98.

Mahroeian, H, dan A. Forozia. 2012. Challenges in managing tacit knowledge: a study on difficulties in diffusion of tacit knowledge in organizations. International Journal of Business and Social Science, 3/1): 303-308.

McAdam, R, dan R. Reid. 2001. SME and large organization perceptions of knowledge management: Comparisons and contrast. Journal of Knowledge Management, 5/3: 231-241.

Nonaka, I, dan H. Takeuchi. 1995. The Knowledge-creating company: How Japanese companies create dynamics of innovation. Oxford University Press.

Nonaka, I, G.V. Krogh, dan S.Voepel. 2006. Organizational knowledge creation theory: evolutionary paths and future advances. Organization Studies, 27: 1179-1208.

Nosek, J.T. 2004. Group cognition as a basis for supporting group knowledge creation and sharing. Journal of Knowledge Management, 8/4: 54-64.

Ramirez, A.M, V.J.G. Morales, dan D.A. Aranda. 2012. Knowledge creation and flexibility of distribution of information. Industrial Management \& Data Systems, 112/2: 166185.

Ramirez, A.M, V.J.G. Morales, dan R.M. Rojas. 2011. Knowledge creation, organizational learning, and their effect on organizational performance. Inzinerine EkonomikaEngineering Economics, 22/3: 309-318.

Raza, A, A.R. Kausar, dan D. Paul. 2006. Culture, cognition and knowledge-based development. Journal of Knowledge Management, 10/): 137-145.

Soedjono. 2005. Pengaruh Budaya Organisasi Terhadap Kinerja Organisasi dan Kepuasan Kerja Karyawan pada Terminal Penumpang Umum di Surabaya. Jurnal Manajemen \& Kewirausahaan, 7/1: 22- 47.

Song, J.H. 2008. The key to organizational performance improvement: A perspective of organizational knowledge. Performance Improvement Quarterly, 21/2: 87-103.

Song, J.H, dan T.J. Chermark. 2008. A theoretical approach to the organizational knowledge formation process: Integrating the concepts of individual learning and learning organization culture. Human Resource Development Review, 7: 424-442.

Sun, P. 2010. Five critical knowledge management organizational themes. Journal of Knowledge Management, 14/4: 507 - 523.

Tseng, S.M. 2010. The correlation between organizational culture and knowledge conversion on corporate performance. Journal of Knowledge Management, 14/2: 269-284.

Ulrich, D, dan J.B. Barney. 1984. Perspective in Organizations: resource dependence, efficiency, and population. Academy of Management Review, 9/): 41-481. 
INOBIS: Jurnal Inovasi Bisnis dan Manajemen Indonesia

Volume 03, Nomor 2, Maret 2020

Rinawati Zailani, Choirun Nisaa'

Venkitachalam, K, dan P. Busch. 2012. Tacit knowledge: review and possible research directions. Journal of Knowledge Management, 16/2: 356-371.

Wernerfelt, B. 1984. A resource-based view of the firm. Strategic Management Journal, 5/2: 11-180. 